\title{
Using Microwave Heating to Completely Recycle Concrete
}

\author{
Heesup Choi 1,2, Myungkwan Lim 1,2*, Hyeonggil Choi ${ }^{3}$, Ryoma Kitagaki³, \\ Takafumi Noguchi ${ }^{3}$ \\ ${ }^{1}$ Department of Civil Engineering, Kitami Institute of Technology, Hokkaido, Japan \\ ${ }^{2}$ Graduated School of Engineering, Hankyong National University, Ansung, Korea \\ ${ }^{3}$ Department of Architecture, The University of Tokyo, Tokyo, Japan \\ Email: ${ }^{*}$ limmk79@naver.com
}

Received 25 March 2014; revised 21 April 2014; accepted 18 May 2014

Copyright (C) 2014 by authors and Scientific Research Publishing Inc.

This work is licensed under the Creative Commons Attribution International License (CC BY). http://creativecommons.org/licenses/by/4.0/

(c) () Op Open Access

\section{Abstract}

The aim of this study was to develop a technique for the complete recycling of concrete based on microwave heating of surface modification coarse aggregate (SMCA) with only inorganic materials such as cement and pozzolanic materials (silica fume, fly ash). The mechanical properties of SMCA, which was produced using original coarse aggregate (OCA) and inorganic admixtures, as well as its separation from the cement matrix and recovery performance were quantitatively assessed. The experimental results showed that micro structural reinforcement of the interfacial transition zone, which is a weak part of concrete, by coating the surface of the OCA with cement and admixtures such as pozzolanic materials can help suppress the occurrence of micro-cracks and improve the mechanical performance of the OCA. Microwave heating was observed to cause micro-cracking and hydrate decomposition. Increasing the void volume and weakening the hydrated cement paste led to the effective recovery of recycled coarse aggregate.

\section{Keywords}

Recycling, Surface Modification, Interfacial Transition Zone, Pozzolanic Reaction, Microwave, Recovery

\section{Introduction}

Concrete, which is used in large quantities in civil engineering and building construction, becomes weak with time; thus, old structures must be demolished and replaced [1] [2]. The handling of old concrete is a major problem

*Corresponding author. 
for society to adhere to the 3R concept (reduce, reuse, and recycle). The accumulation and storage of concrete in huge piles cannot be a long-term solution because of the reduced natural resources and lack of space. Moreover, decreases in road construction work, which is the main use for recycled concrete, are expected to lead to less demand for sub-base coarse material for roads [3] [4]; in the long term, this calls for measures to expand and diversify the use of recycled concrete waste and to use recycled aggregates for concrete manufacture [5]. Thus, research on recycled aggregates is being conducted from various angles worldwide, and the Japanese Industrial Standards (JIS) has been revised for recycled aggregates [6]. However, there are still problems related to the production of high-quality recycled aggregates such as high energy consumption and the generation of large amounts of fine powder during crushing [7] [8]. On the other hand, using low-quality recycled aggregates can lower the concrete performance, which impedes the spread of recycled aggregate use [9] [10]. Because the aggregate resources that can be newly used are limited, an efficient and reliable mechanism for concrete recycling with low energy consumption is necessary. There are a variety of benefits to recycling concrete rather than dumping or burying it in a landfill [2] [11]:

- Keeping concrete debris out of landfills saves space.

- Using recycled material as gravel reduces the need for gravel mining.

- Recycling 1 ton of cement can save 1360 gallons of water and $900 \mathrm{~kg}$ of $\mathrm{CO}_{2}$.

- Using recycled concrete as the base material for roadways reduces the pollution involved in trucking material.

\section{Technical Overview}

Concrete recycling via microwave heating is a completely new technique and is shown in Figure 1 [21] [22]. Admixtures (e.g., pozzolanic materials) improve the chemical bonding and mechanical friction between aggregates in the coating layer of the original coarse aggregate (OCA) surface and cement matrices at the interfacial transition zone (ITZ), which is the weak part of concrete. Thus, recycled coarse aggregate (RCA) can be recovered for concrete structures because the mechanical performance of the concrete is improved, as shown in Figure 2(a) and Figure 2(b). This technique involves coating the OCA with iron oxide $\left(\mathrm{Fe}_{2} \mathrm{O}_{3}\right)$, which has a high dielectric constant, as a binder and then selectively heating and weakening the aggregate interface with microwaves to manufacture RCA following the dismantling of a structure, as shown in Figure 3(a) and Figure 3(b) [5]. This technique allows almost complete recycling of the aggregates by recovering high-quality RCA while using a small amount of energy [21] [22]. This technique allows for a trade off [9] between improvement in the concrete strength and aggregate recovery rate. Concrete fabricated with this technique comprises OCA, surface modification coarse paste (SMCP), surface modification coarse aggregate (SMCA), and $\mathrm{Fe}_{2} \mathrm{O}_{3}$, as shown in Figure 1 [5].

\section{Mechanical Performance of OCA-SMCP-Cement Matrix}

\subsection{Experiment Overview}

In general, because the bond strength between the aggregate and paste is less than the individual tensile strengths of either the aggregate or paste, a crack tends to initiate from the aggregate-paste interface (i.e., ITZ) owing to bleeding in the fresh concrete or a load-induced crack in the hardened concrete [12]. Therefore, the bond strength of aggregate-paste is somewhat directly related with the strength of the concrete, and this shear bond strength is generated by chemical and physical adhesion [13] [14]. In order to review the effectiveness of surface modification at improving the OCA-SMCP (interface)-cement matrix in detail, as shown in Figure 2, a shear bond strength experiment was conducted by coating the OCA surface with either cement or an admixture comprising cement and pozzolans. The changes in mechanical properties were assessed.

\subsection{Experimental Method}

In this experiment, specimens with OCA, SMCP, and a cement matrix structure were fabricated in order to characterize the chemical and physical bonds that form in the interface between the modified aggregate and cement matrices, as shown in Figure 4. The compressive and tensile shear bond strengths were measured at interface angles $(\alpha, \beta)$ of $30^{\circ}, 45^{\circ}$, and $60^{\circ}$, and the failure load at each angle was compared and analyzed [15] [16]. The OCA specimens were cut from crushed hard sandstone (standard density: $2.66 \mathrm{~g} / \mathrm{cm}^{3}$, water absorption ratio: $0.70 \%$ ); the compressive and tensile shear specimens had dimensions of $10 \mathrm{~cm} \times 10 \mathrm{~cm} \times 40 \mathrm{~cm}$ and $10 \mathrm{~cm} \times 10$ 


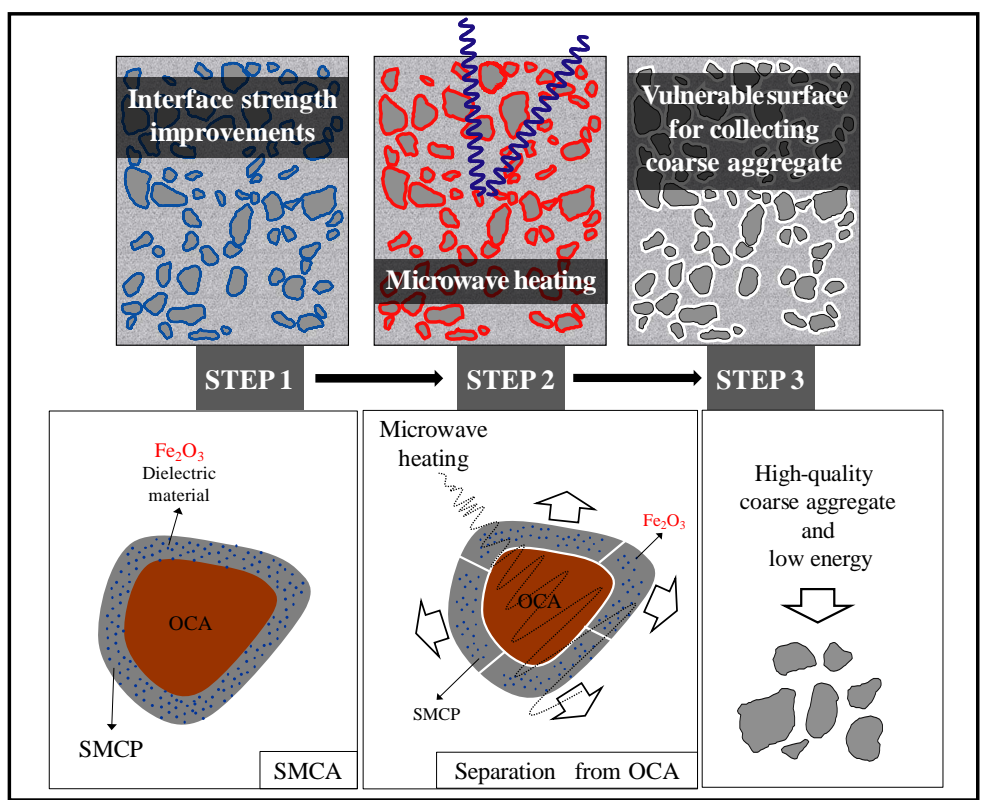

Figure 1. Improvement in concrete strength by modification and recovery by microwave heating [21] [22].

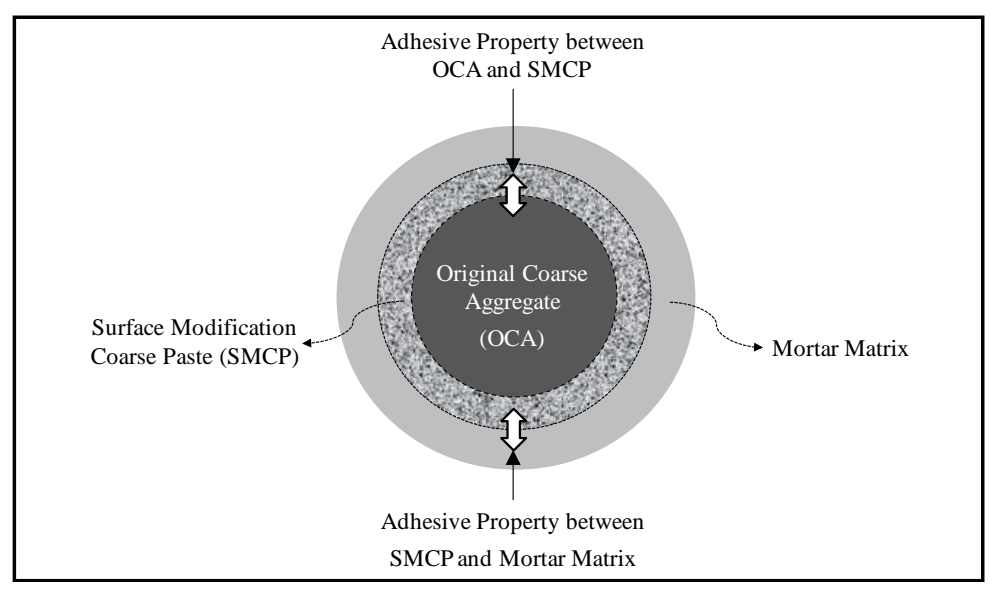

(a)

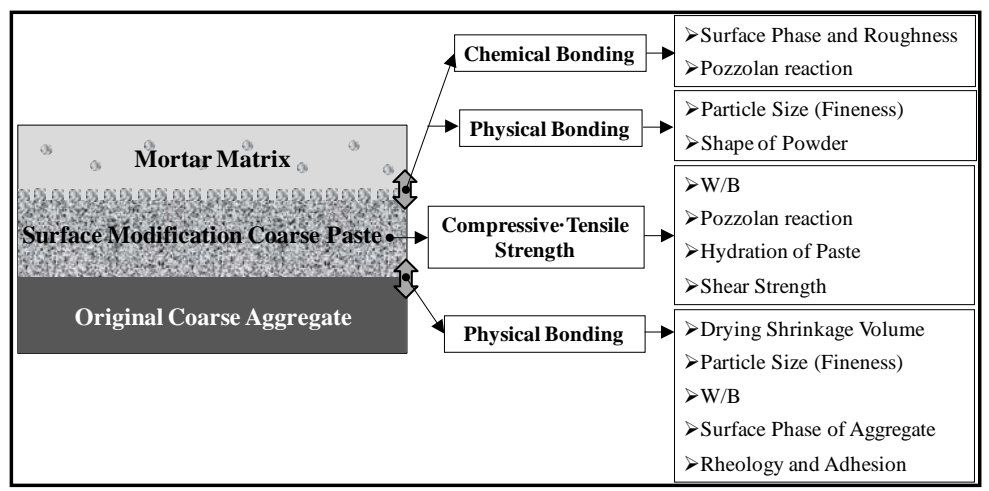

(b)

Figure 2. Mechanism of adhesion between modified aggregate and interface [5]. (a) Concept of surface adhesion of modified aggregate; (b) Control factor of surface adhesion of modified aggregate. 


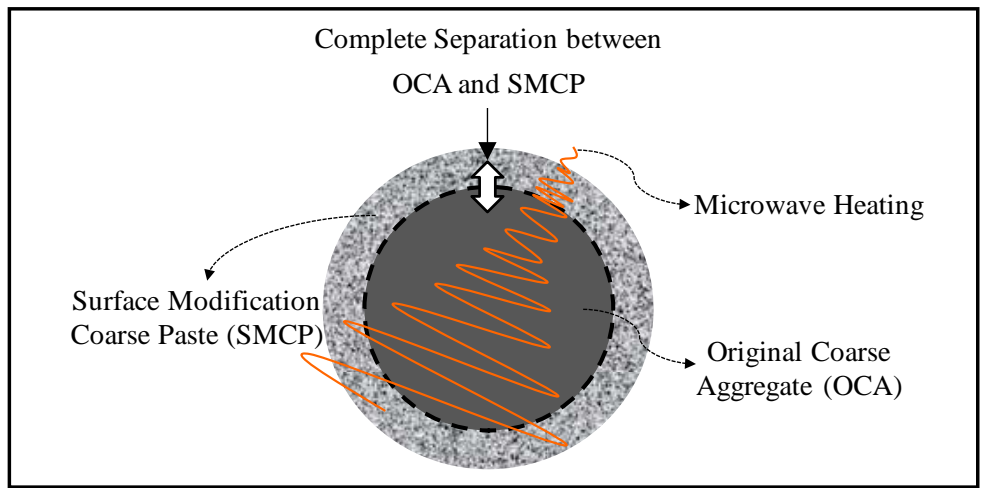

(a)

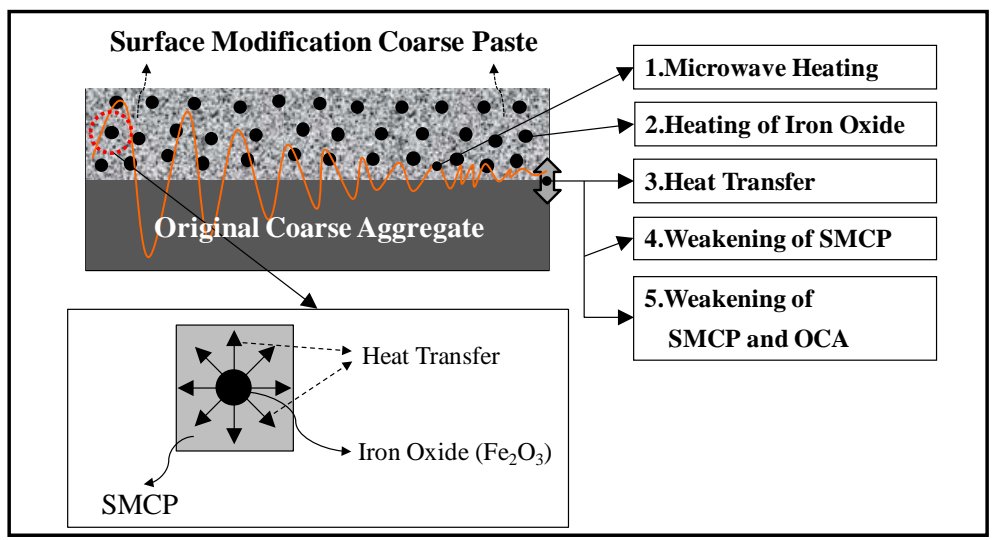

(b)

Figure 3. Mechanism of weakening between OCA and SMCP [5]. (a) Concept of surface separation between OCA and SMCP; (b) Control factor of surface separation of modification aggregate.

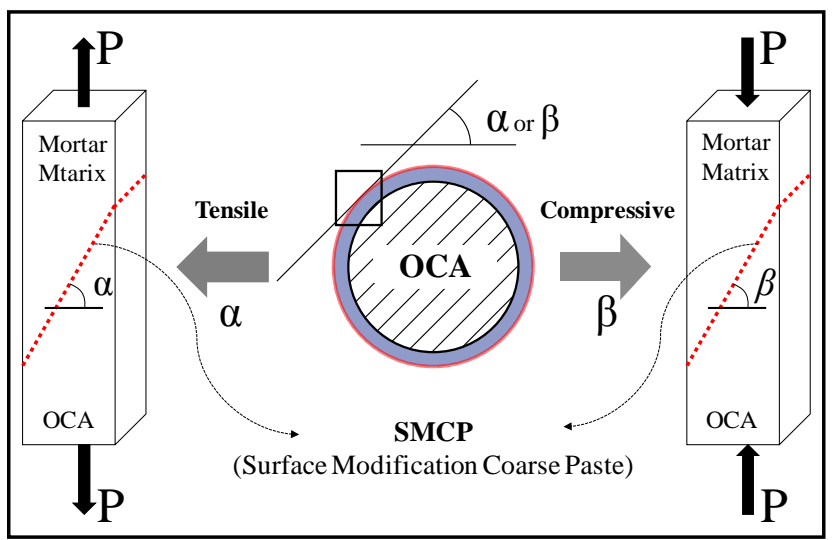

(a)

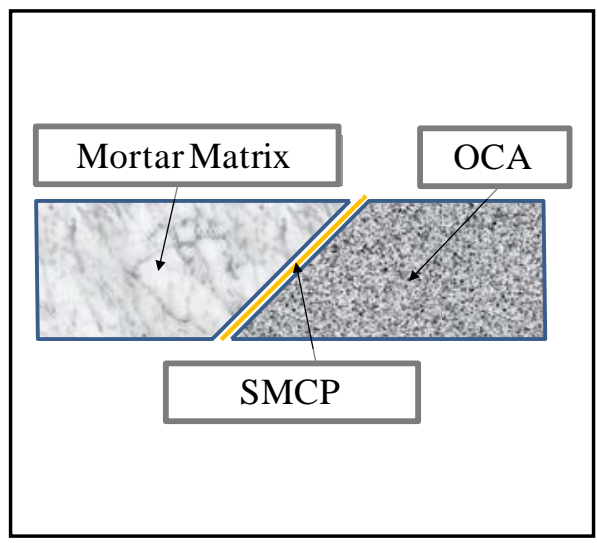

(b)

Figure 4. Outline of shear bond testing of SMCA concrete. (a) Concept of shear bond testing; (b) Manufacture of specimen.

$\mathrm{cm} \times 20 \mathrm{~cm}$, respectively (Table 1). The SMCP was mixed based on the mixing ratio presented in Table 2; for the materials, cement and cement substituted with pozzolanic materials (silica fume, fly ash) were used. The $\mathrm{W} / \mathrm{C}$ ratio for the mortar was set to 55\%; this ratio is generally applied in the field to satisfy the general strength condition given in Table 3. In the experiment, the modified aggregate specimens were cut in advance to ensure that the interface angle would be $30^{\circ}, 45^{\circ}$, and $60^{\circ}$; these were installed in the form before SMCP was coated on 
Table 1. Experimental factors and conditions.

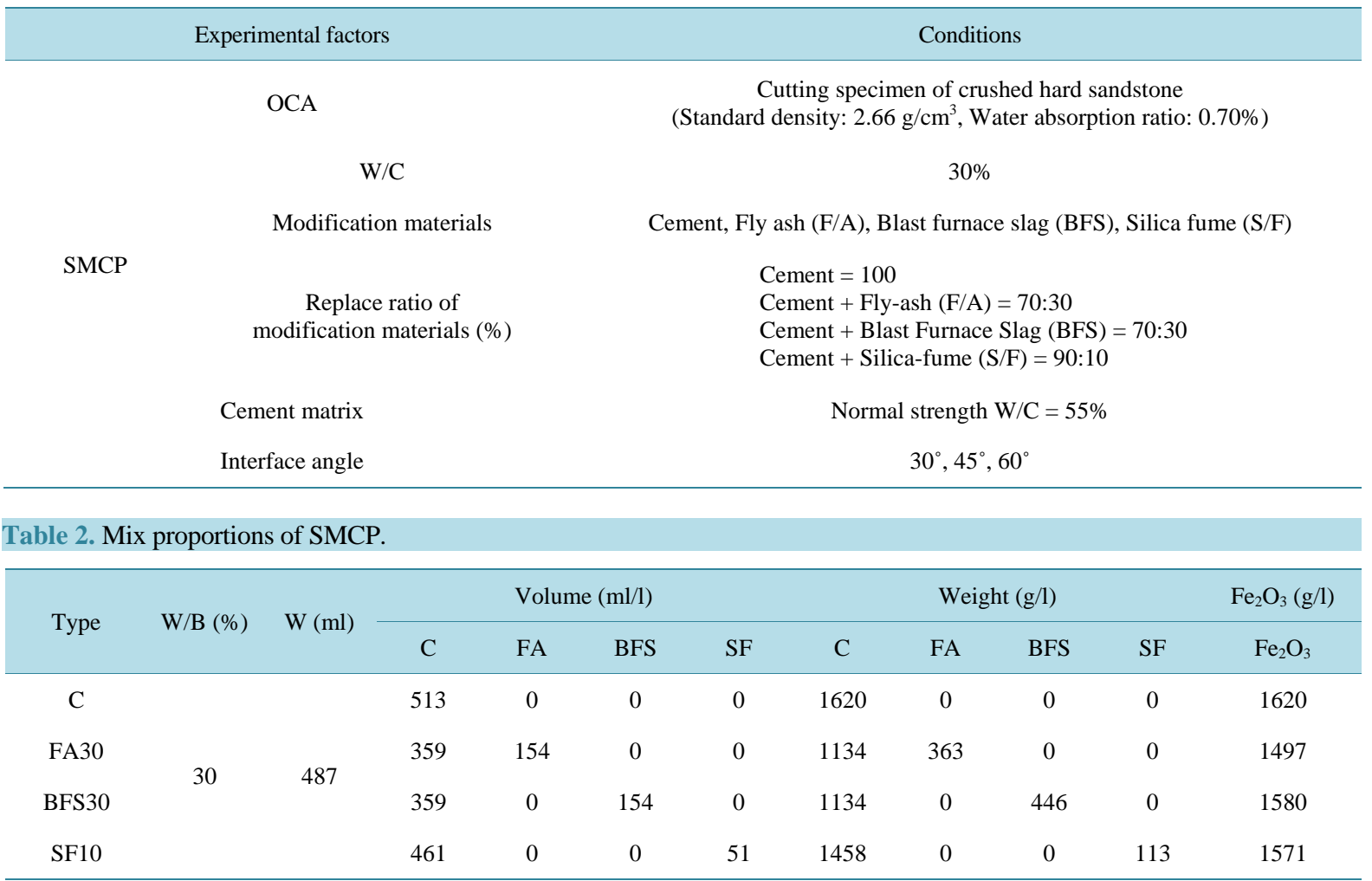

Note: Density of each material (unit: $\mathrm{g} / \mathrm{cm}^{3}$ ). C: Cement: 3.16; FA: Fly ash: 2.22; BFS: Blast furnace slag: 2.91; SF: Silica fume: 2.24.

Table 3. Mix proportion of mortar.

\begin{tabular}{ccccccc}
\hline & & & & & Unit weight $\left(\mathrm{kg} / \mathrm{m}^{3}\right)$ \\
Type & W/C (\%) & Air (\%) & W & C & Fine aggregate & Admixture \\
\hline $\begin{array}{c}\text { OCA's concrete }(\mathrm{O}) \\
\text { SMCA's concrete }(\mathrm{M})\end{array}$ & 55 & $4.5 \pm 1.5$ & 175 & 318 & 833 & $1.59\left(\mathrm{a}^{*}\right)$ \\
\hline
\end{tabular}

Note: O: OCA concrete; M: SMCA concrete; a : Plasticizer.

the specimen surfaces. The specimens were then air-cured for 28 days in a room at constant temperature and humidity $\left(20^{\circ} \mathrm{C}, 60 \% \mathrm{RH}\right)$, and the mortar was placed. In order to prevent failure in the aggregate and cement matrix surface when the specimen was taken out of the form, the specimens were air- and water-cured for 5 and 28 days, respectively, in the room at the same constant temperature and humidity. Then, a load was applied at a rate of $1 \mathrm{~mm} / \mathrm{min}$ to measure the bond failure in the interface. In the tensile shear bond strength test, epoxy resin adhesive was used to attach the specimen to the tensile testing instrument, and the load was applied using a round loop to prevent eccentricity. Table 4 presents the experimental levels of the SMCA concrete.

\subsection{Compressive Shear Bond Strength}

Figure 5 shows the results of the compressive shear bond strength test; the SMCA concrete demonstrated an approximately 50\% increase in strength compared to the OCA concrete regardless of the interface angle. The compressive shear bond strength tended to decrease as the interface angle increased; this was deemed to be caused by the sliding effect resulting from the increase in the interface angle irrespective of the bonding surface. On the other hand, adding silica fume to the SMCP led to higher compressive shear bond strength because of the microfiller effect and pozzolanic reaction. A 30\% substitution with fly ash resulted in the second-highest compressive shear bond strength following the SMCP containing silica fume. Thus, the pozzolanic reaction caused by the 
Table 4. Experimental levels.

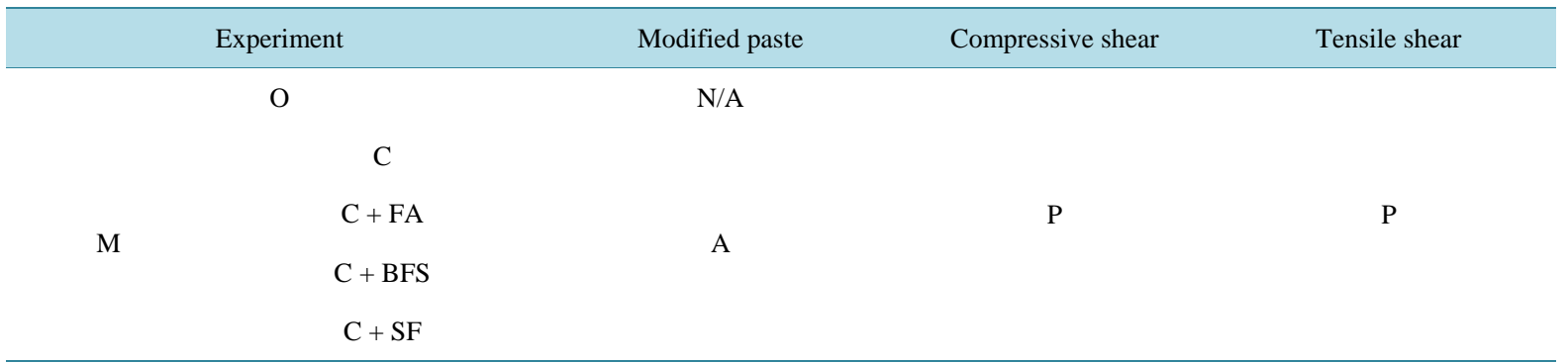

Note: O: OCA; M: Modified coarse aggregate (SMCA concrete), C: Cement; C + FA: Cement + Fly ash; C + BFS: Cement + Blast furnace slag; C + SF: Cement + Silica fume, N/A: Not applicable; A: Application; P: Performed.

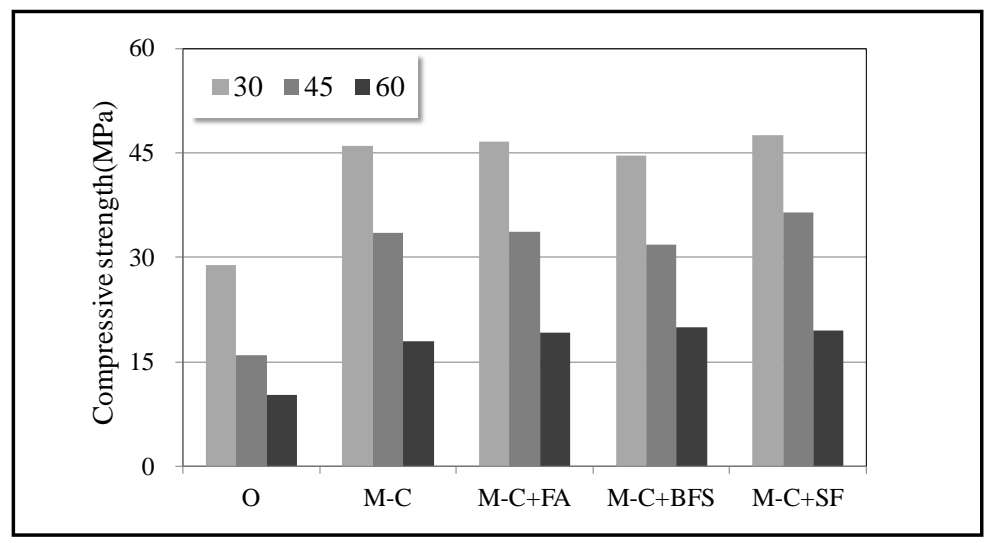

Figure 5. Compressive shear bond strength.

substituted fly ash may improve the strength.

\subsection{Tensile Shear Bond Strength}

Figure 6 shows the results of the tensile shear bond strength test; all of the modified aggregate specimens had improved shear bond strength compared to the OCA. In addition, the tensile shear bond strength was observed to increase with the interface angle. In other words, a larger bonding surface meant a larger area of the microstructure of ITZ was improved, which in turn improved the shear bond strength. In particular, when a pozzolanic material such as silica fume or fly ash was added to the SMCP, the tensile shear bond strength increased even further; this may be a result of the structural densification caused by the micro-filler effect and pozzolanic reaction. Figure 7(a) and Figure 7(b) show the fracture surfaces and scanning electron microscope images of the ITZ for the OCA and SMCA concretes. As shown in Figure 7(a), failure occurred in the ITZ between the OCA and cement matrices, which were observed to contain calcium hydroxide $(\mathrm{C}-\mathrm{H})$ and ettringite. However, failure of the SMCA concrete occurred in the cement matrices and not in the interface, as shown in Figure 7(b). This may indicate that a denser and stronger ITZ with a high level of calcium silicate hydrate (C-S-H) was strengthened by the surface modification treatment and pozzolanic reaction.

\section{Weakening between OCA and SMCP by Microwave Heating}

\subsection{Experiment Overview and Method}

An experiment was carried out to measure the weakening between OCA and SMCP caused by microwave heating (frequency of $2.45 \mathrm{GHz}$ and high-frequency output of $1800 \mathrm{~W}$ ) at heating times of $0,60,120$, or 180 sin the SMCA concrete, as shown in Figure 3. The microwave heating characteristics and changes in the pores before and after heating were measured by mercury intrusion porosimetry (MIP). The temperature was measured using thermography before and after microwave heating was applied, and the temperature characteristics under each condition were assessed (Figure 8). The experimental specimens were manufactured by selecting $\mathrm{O}$ and $\mathrm{M}-\mathrm{C}$ 


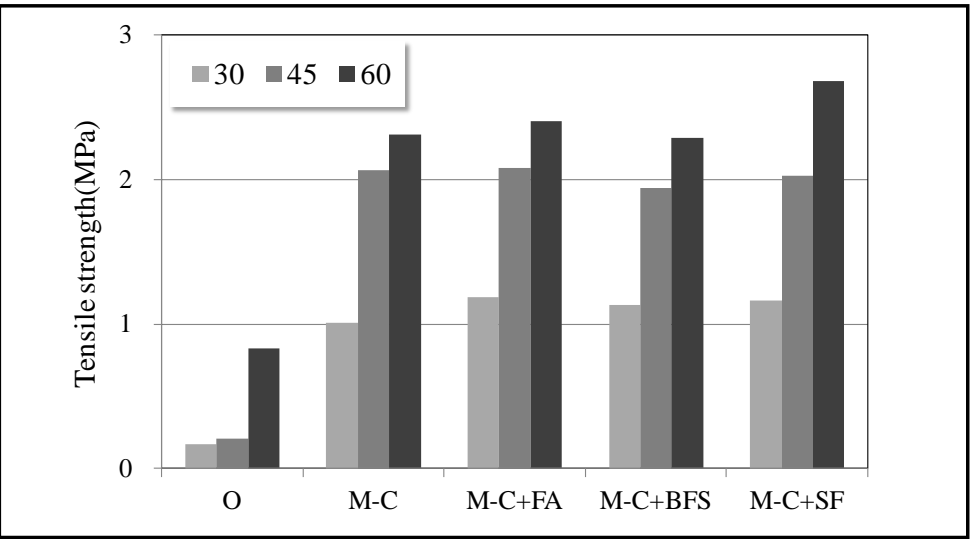

Figure 6. Tensile shear bond strength.
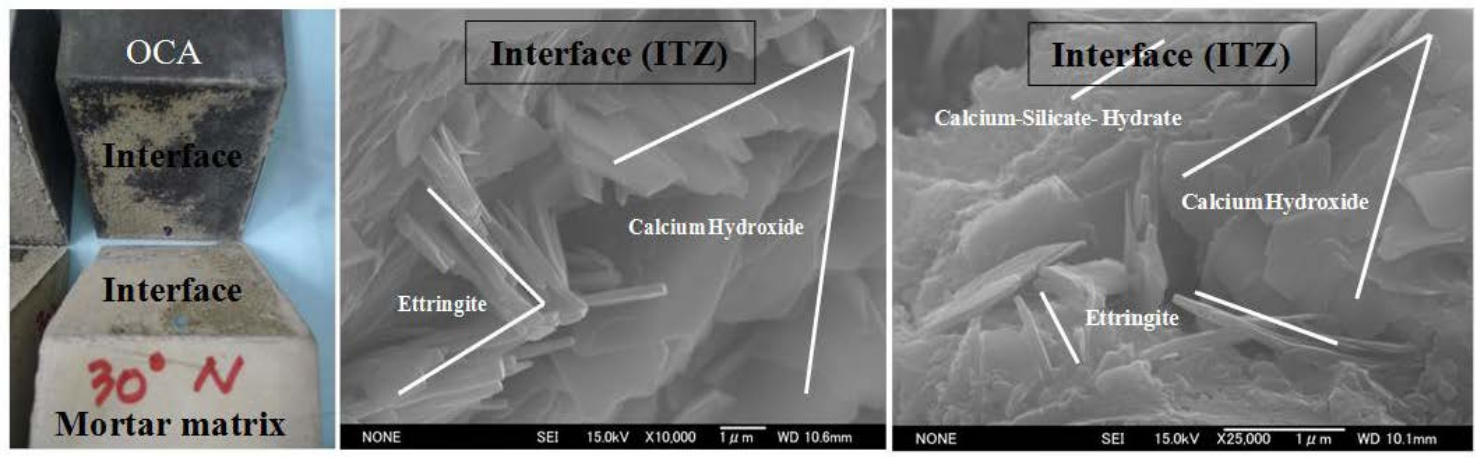

(a)
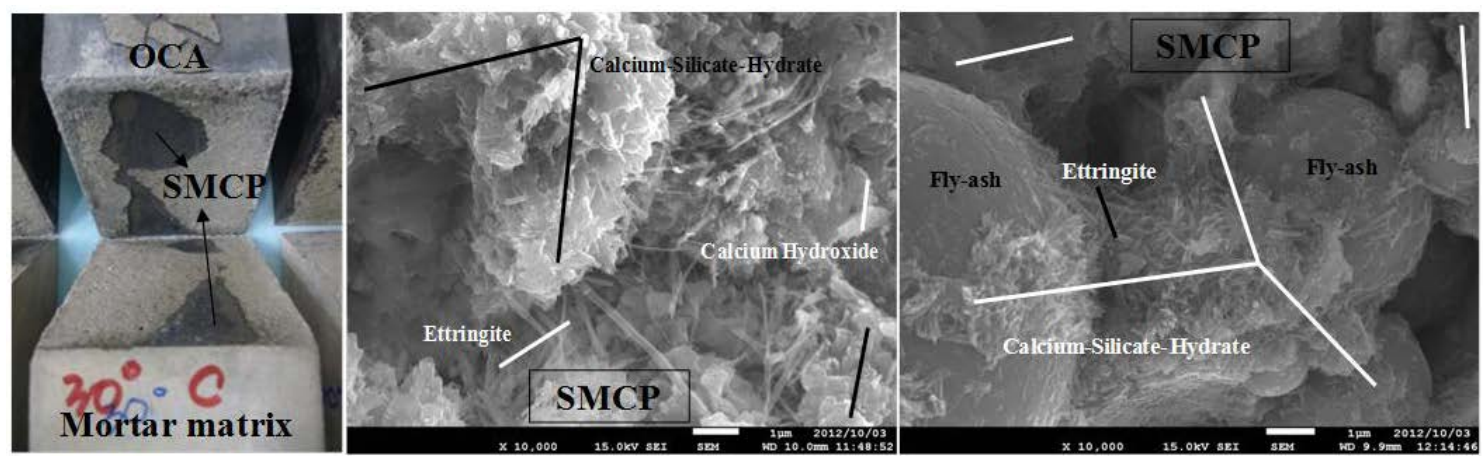

(b)

Figure 7. Fracture surfaces and scanning electron microscope images for ITZ of each concrete specimen. (a) OCA concrete; (b) SMCA concrete.

from the pozzolanic materials in Section 3. Also, aggregates with a significant amount of cement paste attached were collected from the concrete for use as test specimens in the MIP experiment, as shown in Figure 9.

\subsection{Temperature Performance of SMCA by Microwave Heating}

Figure 10 shows the experimental results for the OCA concrete. The temperature increased to $110^{\circ} \mathrm{C}$ after $60 \mathrm{~s}$, $200^{\circ} \mathrm{C}$, after $120 \mathrm{~s}$, and $280^{\circ} \mathrm{C}$ after $180 \mathrm{~s}$. In comparison, the temperature of the SMCA concrete increased to $190^{\circ} \mathrm{C}$ after $60 \mathrm{~s}, 280^{\circ} \mathrm{C}$ after $120 \mathrm{~s}$, and $405^{\circ} \mathrm{C}$ after $180 \mathrm{~s}$, as shown in Figure 10. The SMCA concrete showed a greater temperature increase of approximately $80^{\circ} \mathrm{C}-130^{\circ} \mathrm{C}$ compared to the OCA concrete. Thus, microwave heating was determined to have a greater effect on the former. In particular, when the SMCA was heated for $180 \mathrm{~s}$, the increase in temperature was approximately $130^{\circ} \mathrm{C}$, higher than that of the OCA. This may be due to the 


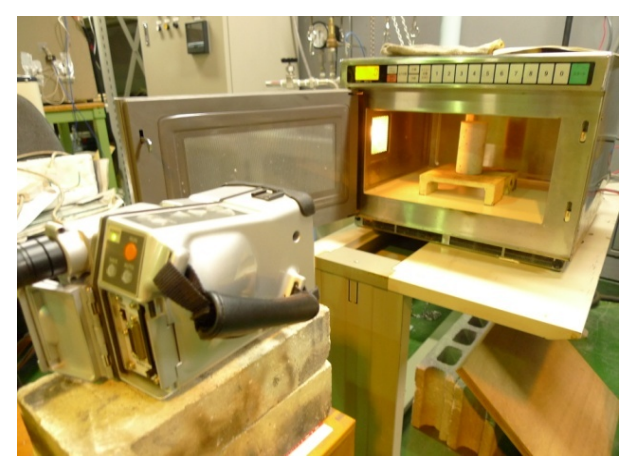

Figure 8. Microwave heating.

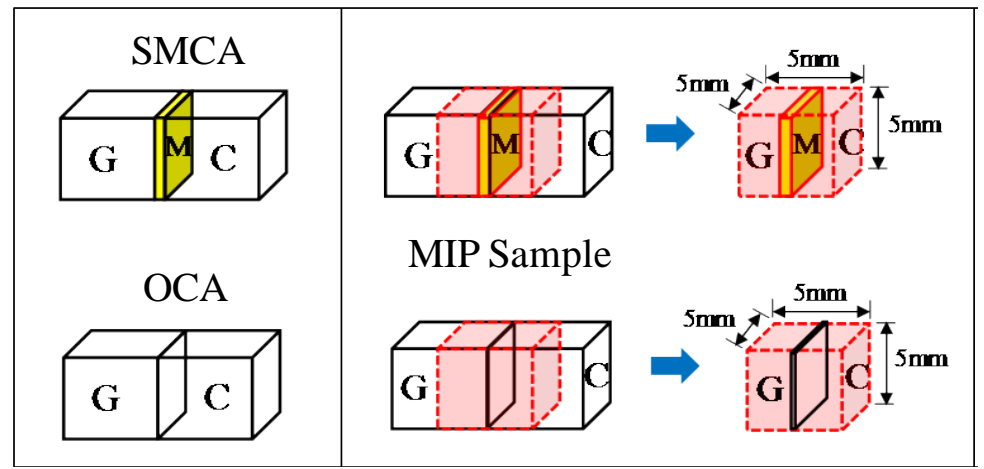

Figure 9. Microwave heating. Note: G: Gravel; M: SMCP; C: Cement matrix.

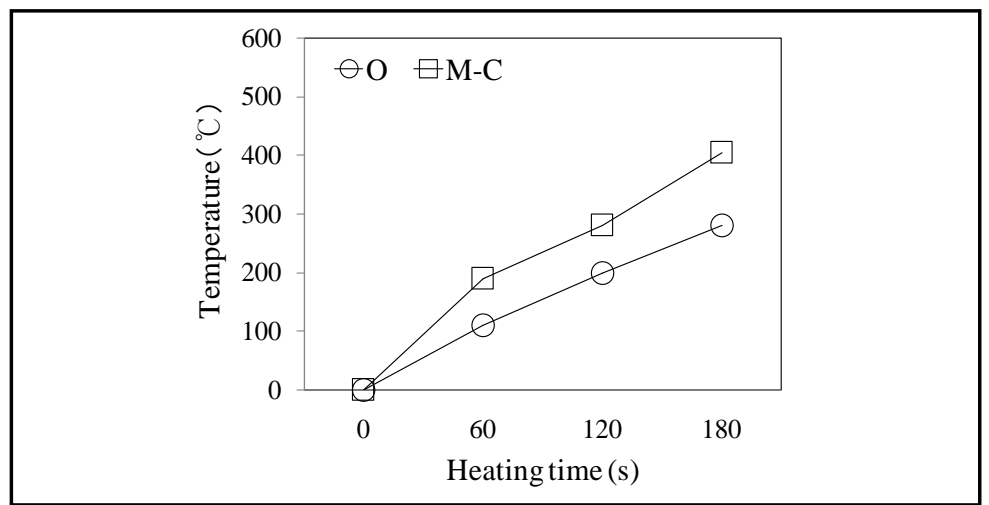

Figure 10. Temperature characteristics of SMCA and OCA with microwave heating.

effective heating of iron oxide [17], which was mixed in the SMCP as a dielectric material, as shown in Figure 11.

\subsection{Weakening of SMCA Due to Changes in Void Volume}

The experimental results showed that the temperatures of the specimens increased because of the thermal conductivity of the iron oxide being heated by the microwaves, as shown in Figure 12 and Figure 13. The total increase in void volume and peak of the pore distribution moved to the part with the largest void volume. In particular, when the heating time was over $180 \mathrm{~s}$, the number of pores with a diameter of $0.05 \mu \mathrm{m}$ or less decreased, whereas pores with a diameter of $0.05-0.1 \mu \mathrm{m}$ moved toward spores with a diameter of $0.1 \mu \mathrm{m}$ as the void volume increased (Figure 13). As shown in Figure 14, when the heating time was over $180 \mathrm{~s}$, the void volume 


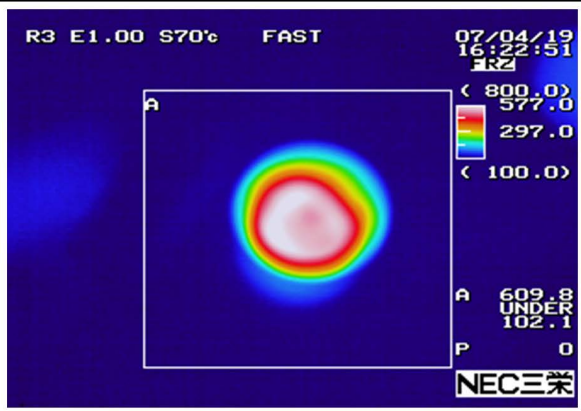

Figure 11. Heating of iron oxide by microwave heating $\left(577^{\circ} \mathrm{C}\right.$ after $\left.30 \mathrm{~s}\right)$.

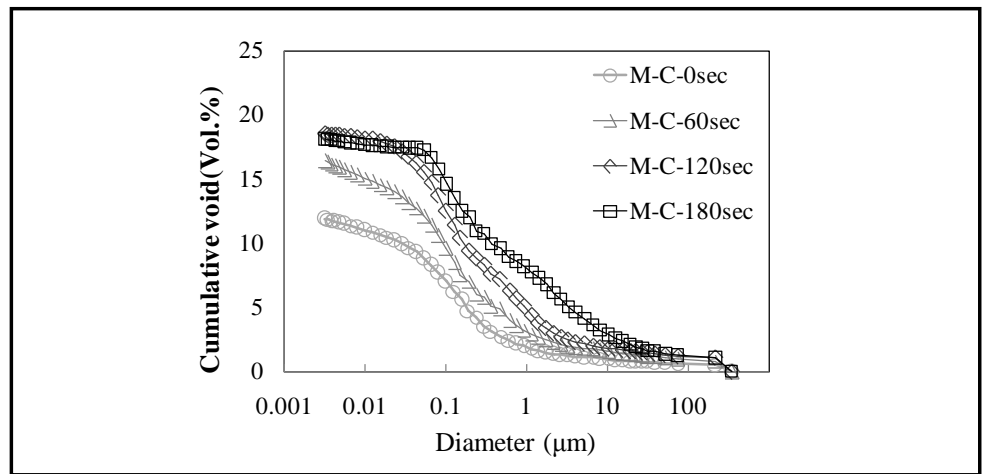

Figure 12. Cumulative void size distribution of SMCA.

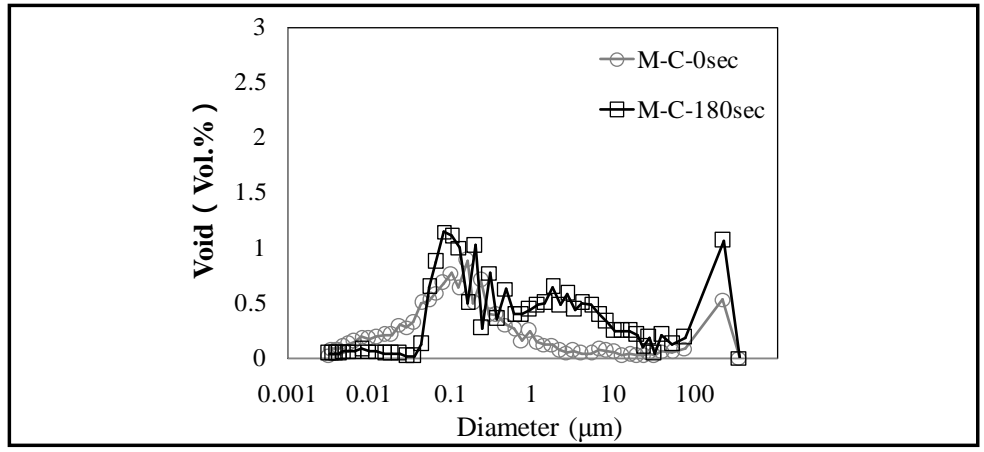

Figure 13. Void size distribution of SMCA.

of the SMCA concrete was slightly higher than that of the OCA concrete. The increase in the concrete porosity [18] [19] because of microwave heating may represent the weakening of the cement paste around the ITZ and aggregate. Thus, the increase in pores in the SMCA concrete because of microwave heating may result from the evaporation of bound water caused by the decomposition of calcium hydroxide and C-S-H hydrates and the occurrence of micro-cracks in the concrete [20].

\section{Performance Review of SMCA Concrete}

\subsection{Experiment Overview and Method}

Concrete is generally composed of cement, water, and fine and coarse aggregates. However, with respect to the SMCA concrete, the surface of the OCA was coated with cement paste. This required that the modified paste be reflected in the mixing design, as shown in Figure 15. In the mixing design, the amount of coarse aggregate coated with an admixture can be increased. Thus, the amount of SMCP coated on the coarse aggregate can be excluded from the amounts of cement and water in the mixing ratio, and the amounts of cement, water, and 


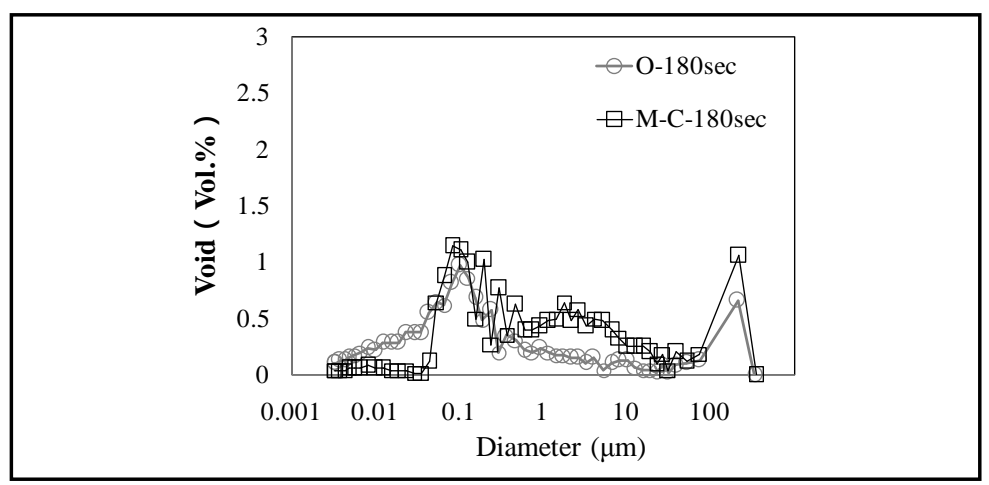

Figure 14. Void size distribution of each aggregate.

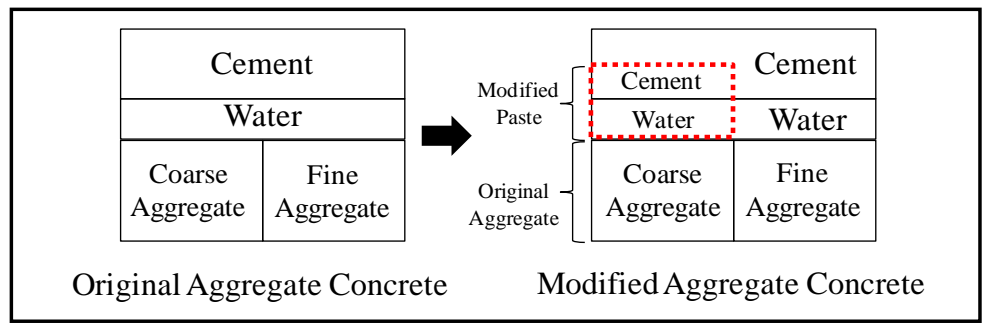

Figure 15. Ratios of constituents in concrete (Note: Materials $/ \mathrm{m}^{3}$ ) [5].

OCA for the OCA and SMCA concretes can be the same [5]. In this experiment, OCA and SMCA concrete specimens with a water-cement (W/C) ratio of $55 \%$ were compared. In order to achieve equal characteristics for the fresh specimens for the comparison, the W/C ratio of the SMCA concrete and amount of chemical admixture were adjusted as shown in Table 5. Using the above method, the same amount of cement was applied to the mixing design for the OCA and SMCA. As the binder for the surface admixture, only cement and cement with admixtures (e.g., pozzolanic material) were used with a W/C ratio of 30\%. The mixing percentage of the surface admixture is shown in Table 6. Based on the mechanical performance and weakening of the SMCA concrete in Sections 3 and 4, the compressive and splitting tensile strengths of the SMCA concrete were examined in this experiment to assess the improvement in the mechanical properties. The recovery rates of RCA by microwave heating (frequency of $2.45 \mathrm{GHz}$ and high-frequency output of $1800 \mathrm{~W}$ ) for $0,60,120$, and $180 \mathrm{~s}$ were measured to assess the aggregate recovery characteristics.

For the OCA used in this experiment, the parent materials were collected from a rocky mountain, crushed with a jaw crusher, and sorted by diameter from $5 \mathrm{~mm}$ to $20 \mathrm{~mm}$. Then, the particle size distribution was adjusted to satisfy the standard diameter prescribed in JIS A 1102 (standard for aggregate sieving test), and the density and water absorption ratio of the OCA and SMCA specimens (only cement and cement with pozzolanic materials, respectively) were measured in accordance with JIS A 1110 (standard for coarse aggregate density and water absorption test). The results of the preliminary experiment showed that the density of OCA with a modified surface was higher than that with no surface modification by $1 \%-1.5 \%$, as shown in Table 7 . This may be because the SMCP with a low W/C ratio contained high-density iron oxide, which resulted in the ITZ microstructure becoming more compact. On the other hand, the water absorption ratio also increased. This was due to the cement paste forming a thin film on the OCA surface, which resulted in the OCA and SMCP absorbing water. However, the OCA and SMCA in this experiment satisfied the criteria prescribed in JIS A 5021 (standard for concrete using recycled aggregate $\mathrm{H}$ ) for $\mathrm{H}$ class of RCA, which can be used for structural aggregate. Thus, the water absorption ratio was not expected to cause any potential problems in this experiment.

\subsection{Mechanical Properties of SMCA Concrete}

The compressive and splitting tensile strength tests were performed based on JIS A 1108 and JIS A 1113. For the mechanical properties, the compressive and splitting tensile strengths of each SMCA concrete specimen were higher than those of the OCA concrete specimens by 5\% - 12\%, as shown in Figure 16 and Figure 17. The 
Table 5. Mix proportions of concrete.

\begin{tabular}{|c|c|c|c|c|c|c|c|c|c|}
\hline \multirow{2}{*}{ Type } & \multirow{2}{*}{$\begin{array}{l}\mathrm{W} / \mathrm{C} \\
(\%)\end{array}$} & \multirow{2}{*}{$\begin{array}{l}\text { Slump } \\
(\mathrm{mm})\end{array}$} & \multirow{2}{*}{$\begin{array}{l}\text { Air } \\
(\%)\end{array}$} & \multirow{2}{*}{$\begin{array}{l}\mathrm{G}_{\max } \\
(\mathrm{mm})\end{array}$} & \multicolumn{4}{|c|}{ Unit weight $\left(\mathrm{kg} / \mathrm{m}^{3}\right)$} & \multirow{2}{*}{$\begin{array}{c}\text { Admixture } \\
(\%)\end{array}$} \\
\hline & & & & & $\mathrm{W}$ & $\mathrm{C}$ & S & G & \\
\hline OCA's concrete (O) & & & & & 175 & 318 & 833 & 961 & $\mathrm{C} \times 0.5\left(\mathrm{a}^{*}\right)$ \\
\hline SMCA's concrete (M) & 55 & $180 \pm 25$ & $4.5 \pm 1.5$ & 20 & 175 & 311 & 833 & 982 & $\mathrm{C} \times 0.9\left(\mathrm{a}^{*}\right)$ \\
\hline
\end{tabular}

Note: O: OCA concrete; M: SMCA concrete; $a^{*}$ : Plasticizer.

Table 6. Mix proportions of modification paste.

\begin{tabular}{cccccc}
\hline W/B (\%) & Water (g) & Binder (g) & $\mathrm{Fe}_{2} \mathrm{O}_{3}(\mathrm{~g})$ & Superplasticizer (g) & $\mathrm{Table} \mathrm{flow} \mathrm{(mm)}$ \\
\hline 30 & 21 & 70 & $\mathrm{~B} \times 100 \%$ & $\mathrm{~B} \times(1.9 \%-2.5 \%)$ \\
\hline
\end{tabular}

Note: Based on $1 \mathrm{~kg}$ of OCA.

Table 7. Type and properties of each coarse aggregate.

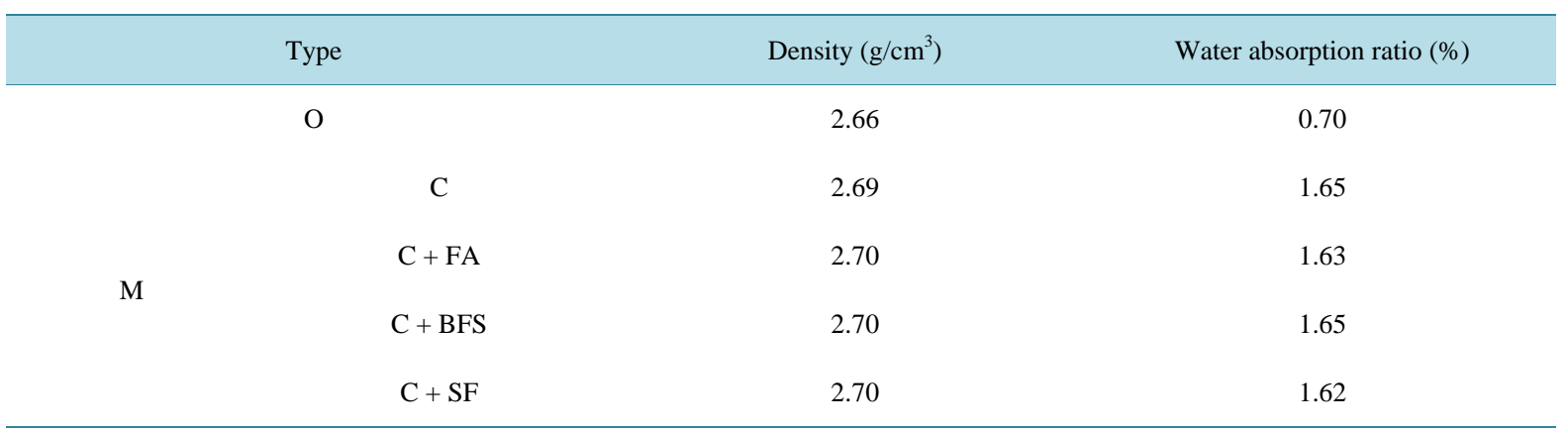

Note: O: OCA (OCA concrete); M: Modified coarse aggregate (SMCA concrete), C: Cement; C + FA: Cement + Fly ash; C + BFS: Cement + Blast furnace slag; C + SF: Cement + Silica fume.

improved strength of the modified aggregate concrete was due to the reinforced physical and chemical bonding between the modified paste and cement matrices, which was caused by the increased mechanical friction resulting from the particle size and shape of the iron oxide and the SMCP coating effect on the ITZ [5]. In addition, the SMCA concrete using pozzolanic materials (silica fume and fly ash) showed an increase in strength of approximately $8 \%$ after 7,14 , and 28 days of curing compared to the SMCA concrete using only cement (Figure 16). The splitting tensile strength test results showed an improvement in strength of approximately $5 \%$ after 7 , 14, and 28 days of curing (Figure 17). As noted in Section 2, when pozzolanic materials such as silica fume and fly ash were added to the SMCP, the micro-filler effect and pozzolanic reaction caused the ITZ structure to become denser.

\subsection{Recovery Properties of SMCA Concrete}

As shown in Figure 18(a) and Figure 18(b), when the microwave heating times were 0 and 60 s, the RCA recovery rate for the SMCA concrete was equivalent to or slightly lower than that of the OCA concrete. This may be due to the enhanced bonding caused by the SMCP coating between the OCA and cement matrices. On the other hand, when the microwave heating times were 120 and $180 \mathrm{~s}$, the recovery rate for the SMCA concrete became substantially lower than that of the OCA concrete regardless of the admixture (cement only and cement with pozzolanic materials). When the heating time was $120 \mathrm{~s}$, the temperature reached $300^{\circ} \mathrm{C}$, which is the weakening temperature of cement paste [5] [6]. This was the point at which the recovery rate began to differ. In particular, when the heating time was180 s, the recovery rate of RCA for the SMCA concrete reached nearly $100 \%$; thus, the microwaves were concluded to effectively heat the dielectric material (iron oxide) present in the SMCP. This result could be predicted by the RCA recovery rates for both the OCA and SMCA concrete specimens after $180 \mathrm{~s}$ of microwave heating, as shown in Figure 19. 


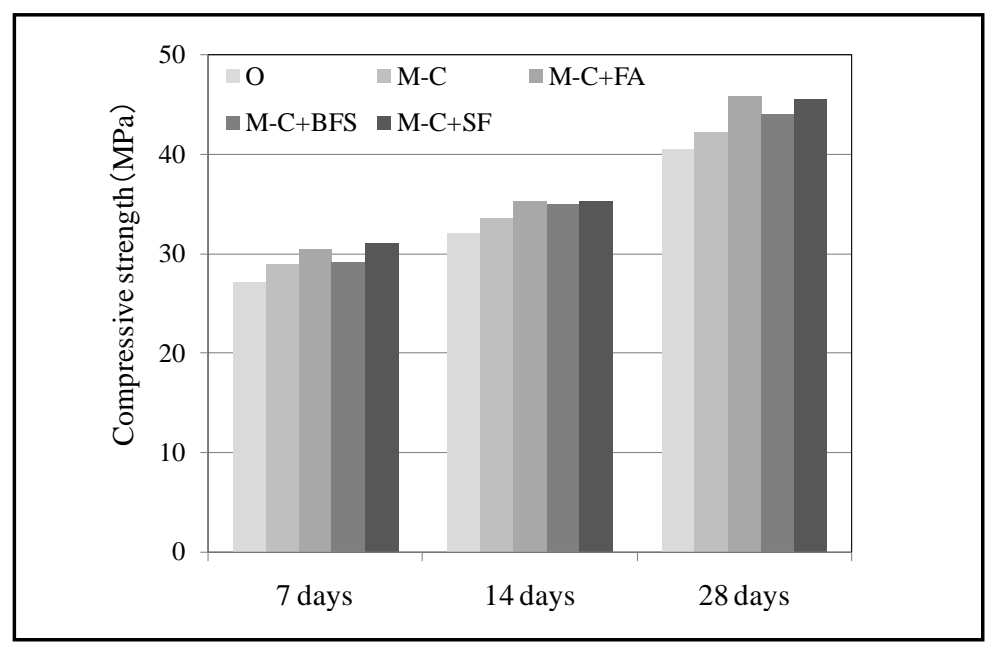

Figure 16. Comparison of strength.

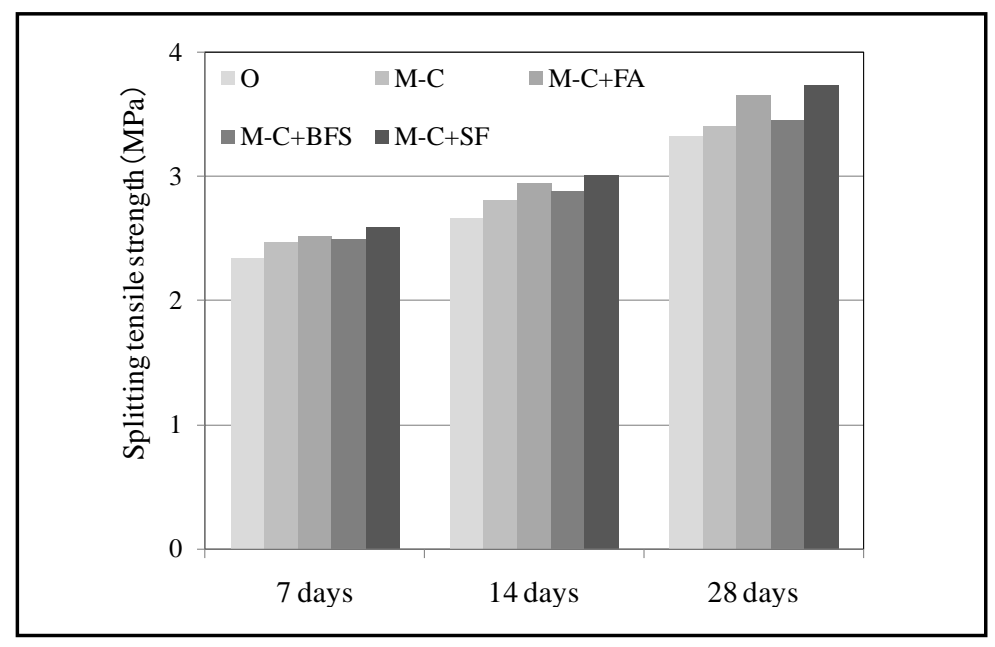

Figure 17. Splitting tensile strength.

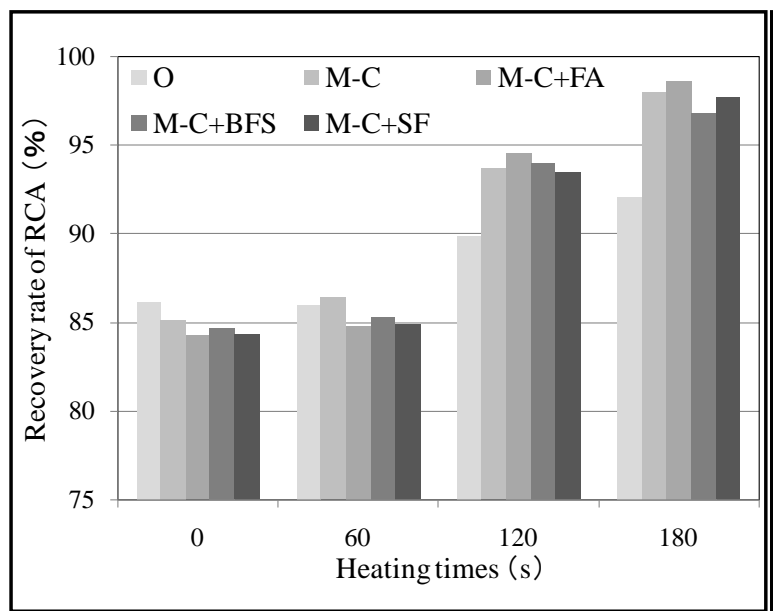

(a)

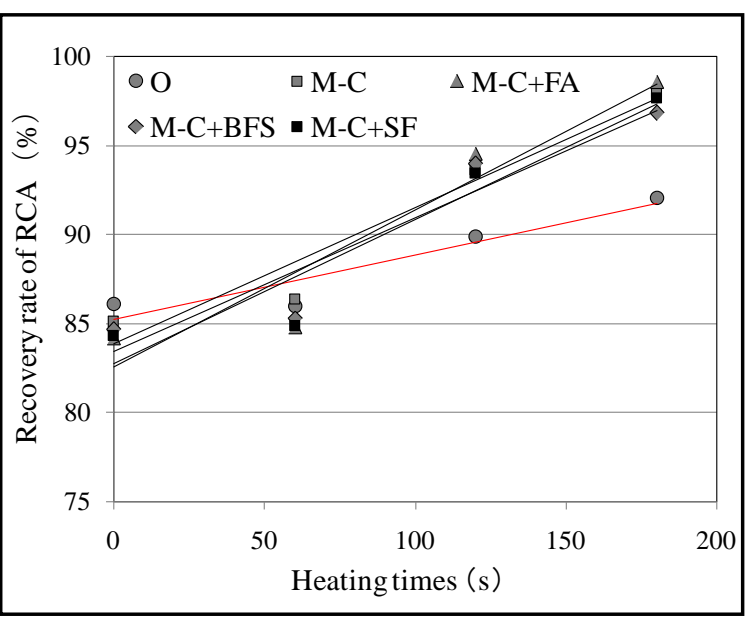

(b)

Figure 18. Recovery rate of RCA of each concrete specimen by microwave heating. (a) RCA recovery rates; (b) Comparison of RCA recovery rates. 


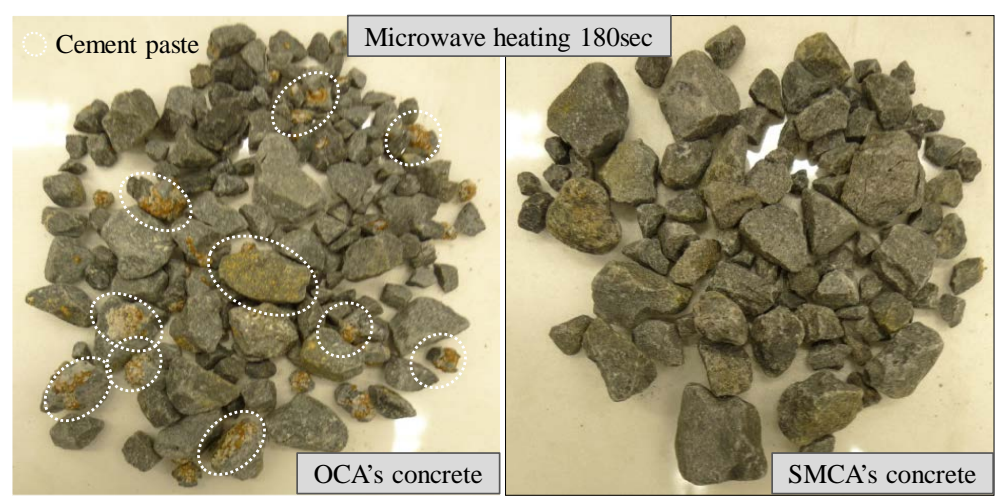

Figure 19. Comparison of RCA from each type of concrete.

\section{Conclusions}

The following conclusions were made based on the results of the experiments conducted to examine the mechanical properties and recovery performance of the SMCA concrete with admixtures and microwave heating.

1) When the W/C ratio was 55\%, the improvements in the compressive strength and split tensile strength, including the shear bond strength, were confirmed to be due to the SMCP coating; the ITZ structure was made denser by the admixtures (only cement and pozzolanic materials).

2) When the SMCA concrete containing iron oxide $\left(\mathrm{Fe}_{2} \mathrm{O}_{3}\right)$, was heated with microwaves, the temperature increased more significantly compared to the OCA concrete. In particular, when the microwave heating time was $180 \mathrm{~s}$, the maximum temperature was over $400^{\circ} \mathrm{C}$, and micro-cracks occurred in the concrete along with an increased void volume caused by dehydration of the hydrates. Based on these results, the microwaves effectively heated the iron oxide contained in the SMCP.

3) The RCA recovered after microwave heating for $180 \mathrm{~s}$ contained less than $5 \%$ of paste and fine aggregate, regardless of the admixture. The recovered RCA was very similar to the OCA, which proves the feasibility of recovering high-quality RCA. Thus, microwave heating was determined to weaken binders containing a dielectric material for efficient recovery of RCA.

The mechanical performance of SMCA can be improved by the use of inorganic materials and microwave heating to effectively recover RCA.

\section{References}

[1] Noguchi, T. and Tamura, M. (2001) Concrete Design towards Complete Recycling. Structural Concrete Journal of the Fib, 2, 155-167.

[2] Noguchi, T. (2008) Resource Recycling in Concrete: Present and Future. Stock Management for Sustainable Urban Regeneration, 4, 255-274.

[3] Hendriks, Ch.F. and Janssen, G.M.T. (2001) Construction and Demolition Waste: General Process. HERON, 46, 79-88.

[4] Shima, H., Tateyashiki, H., Matsuhashi, R. and Yoshida, Y. (2005) An Advanced Concrete Recycling Technology and its Applicability Assessment through Input-Output Analysis. Journal of Advanced Concrete Technology, 3, 53-67. http://dx.doi.org/10.3151/jact.3.53

[5] Choi, H.S., Kitagaki, R. and Noguchi, T. (2014) Effective Recycling of Surface Modification Aggregate using Microwave Heating. Journal of Advanced Concrete Technology, 12, 34-45. http://dx.doi.org/10.3151/jact.12.34

[6] Choi, H.S., Kitagaki, R. and Noguchi, T. (2012) A Study on the Completely Recovery of Surface Modification aggregate using Microwave and Effective Utilization. Proceedings of the 5th ACF International Conference, Pattaya, October 2012, Session 1-2, ACF2012-0093, 41-46.

[7] Kunio, Y. (2003) A Study on the Manufacturing Technology of High-Quality Recycled Fine Aggregate. Japan Concrete Institute, 25, 1217-1222.

[8] Shima, H. and Tateyashiki, H. (1999) New Technology for Recovering High-Quality Aggregate from Demolished Concrete. Proceedings of the 5th International Symposium on East Asian Recycling Technology, The M.M.P.I. in Japan 1999, 106-109.

[9] Tamura, M., Tomosawa, F. and Noguchi, T. (1997) Recycle-Oriented Concrete with Easy-to-Collect Aggregate. Ce- 
ment Science and Concrete Technology, 51, 494-499.

[10] Tsujino, M., Noguchi, T., Tamura, M., Kanematsu, M. and Maruyama, I. (2007) Application of Conventionally Recycled Coarse Aggregate to Concrete Structure by Surface Modification Treatment. Journal of Advanced Concrete Technology, 5, 13-25. http://dx.doi.org/10.3151/jact.5.13

[11] Value Engineering Benefits (2010) Concrete Recycling.org. Retrieved 2010-04-05.

[12] Mehta, P.K. and Moneiro, P.J.M. (2006) Concrete: Microstructure, Properties and Materials. McGraw-Hill Companies, New York.

[13] Diamond, S. and Huang, J. (2001) The ITZ in Concrete. Cement and Concrete Composite, 23, 59-64.

[14] Elsharief, A., Cohen, D. and Olek, J. (2003) Influence of Aggregate Size, Water Cement Ratio and Age on the Microstructure of the Interfacial Transition Zone. Cement and Concrete Research, 33, 1837-1849. http://dx.doi.org/10.1016/S0008-8846(03)00205-9

[15] Robin, P.J. and Austin, S.A. (1995) A Unified Failure Envelope from the Evaluation of Concrete Repair Bond Tests. Magazine of Concrete Research, 47, 57-68. http://dx.doi.org/10.1680/macr.1995.47.170.57

[16] Austin, S., Robins, P. and Pan, Y.G. (1999) Shear Bond Testing of Concrete Repair. Cement and Concrete Research, 29, 1067-1076. http://dx.doi.org/10.1016/S0008-8846(99)00088-5

[17] McGill, S.L., et al. (1988) The Effects of Power Level on the Microwave Heating of Selected Chemicals and Minerals. Proceedings of the MRS Symposium, Nevada, April 1988, 124.

[18] Schneider, U. (1982) Behavior of Concrete at High Temperatures. Deutscher Ausschuss für Stahlbeton, Berlin, 28-33.

[19] Bazant, Z.P. and Kapaln, M.F. (1996) Concrete at High Temperatures: Material Properties and Mathematical Models. Prentice Hall, Upper Saddle River.

[20] Takeo, A., Fukujiro, F., Kuniyuki, T., Kenji, K. and Isao, K. (1999) Mechanical Properties of High-Strength Concrete at High Temperatures. Architectural Institute of Japan, 515, 163-168.

[21] Tsujino, M., Noguchi, T., Kitagaki, R. and Nagai, H. (2010) Completely Recyclable Concrete of Aggregate-Recovery Type by a New Technique Using Aggregate Coating. Architectural Institute of Japan, 75, 17-24.

[22] Tsujino, M., Noguchi, T., Kitagaki, R. and Nagai, H. (2011) Completely Recyclable Concrete of Aggregate-Recovery Type by Using Microwave Heating. Architectural Institute of Japan, 76, 223-229. 